\title{
Ethics Do Matter, But Where?
}

\author{
Peter J. O’Brien
}

\begin{abstract}
The implications of social work being an ethics-based profession are explored. Conduct toward colleagues in the discharge of ethical practices is a focus of this article. The author's view is that other disciplines involved in mental health, for example, psychiatry, family physicians, psychology, nursing, pastoral services, education, and rehabilitation therapy, share these values. As such, these themes are relevant across many professional disciplines. The article's intent is to promote discussion as to how we cultivate a collective demeanor as social workers that is congruent with our most hallowed values and principles, namely, social justice, ethical practice, fairness and respect for all people. An examination of daily practices in the workplace and suggested remedies to enhance ethical conduct, including a series of questions we can ask ourselves, are offered.
\end{abstract}

Keywords: Ethics, ethical conduct, workplace congruence

The purposes of this article are threefold: 1) to identify a gap in the existing social work literature regarding congruence between some of our fundamental values and principles such as social justice, ethical probity and respect, and practices towards one another within the work environment; 2) to promote a dialogue about the importance of congruence between social work values and principles that we hold as sacred and our relationships and interactions, not just with clients, but with one another; and 3) to suggest ways to promote ethical practice.

Interactions that reflect lapses in moral judgment are part of the human condition. However, when ethically dubious conduct is relentless, systematic, and accompanied by an absence of accountability we risk entering the realm of moral turpitude. When such conduct is practiced, reflection will not suffice. Action is imperative.

\section{Ethical Congruence Applies to Colleagues as Well as Clients}

The premise of this article is that colleagues, not just clients, should be considered when social workers make a commitment to ethical practice in the discharge of our duties. As such, when we "...demean, disrespect, harass or otherwise mistreat those in the workplace..." we are "...violating the Code of Ethics" (MacDonald, 2007, p. 14). MacDonald further states that "Social work is an ethics-based profession and social workers are expected to support the philosophy behind the Code of Ethics, not view it simply as a list of rules to follow" (p. 14). Social work's foundation in ethics (Freire \& Moch, 1987; Hugman, 2005; Reamer, 2001; Weinberg \& Campbell, 2014) suggests that there is incongruence between values and actions if we tolerate mistreatment of colleagues - worse if we perpetrate the harm. This article is an invitation to discuss these ideas and to foster a clearer vision of what it means to be social worker.

Peter J. O'Brien, MSW, RSW, is a Clinical Consultant for Alberta Health Services, Shared Mental Health Care, in Calgary Alberta.

Copyright (C) 2014 Advances in Social Work Vol. 15 No. 2 (Fall 2014), 261-277 


\section{Situating the Author's Context}

The author is trained as a social worker and has worked as a mental health therapist for 25 years, both in hospital settings and in the community. The questions and ideas raised herein have been stimulated by observation and discussions with countless individuals of all ranks employed in the mental health and social service sectors throughout the larger community. Social workers and therapists often talk informally about troubling interactions with colleagues. The bewilderment or distress articulated frequently stems from disregard for respect, healthy communication skills, fairness, or social justice in the workplace. Constructive responses are called for.

\section{Literature Review}

There appears to be a gap in the existing social work literature related to incongruence between social work values and principles and practices in contemporary work environments. Much is written about fundamental social work principles such as self-determination (Hepworth, Rooney, Rooney, Strom-Gottfried, \& Larsen, 2010), respect (Reamer, 2013), equality (Austin, 2013), social justice (Hong \& Hodge, 2009; Rountree \& Pomeroy, 2010), empathy (Gerdes, 2009), and being a value-based profession (Ferguson \& Lavalette, 2007; Reisch \& Jani, 2012). A focus in social work literature is on teaching our Code of Ethics (Congress, 2000; Johns \& Crockwell, 2009), learning a formal process for ethical decision-making (Boland, 2006) or considering its application in work with clients (Landau, 2000; Manning, 1997; Mattison, 2000). The importance of these principles in order to be effective in our work with clients is commonly amplified (Mitchell et al., 2012). However, there is a lack of discussion in the literature concerning how values and ethics inform interactions with colleagues. Of note, similar observations have been made about the paucity of articles examining ethical practices among professional ethicists in the health care system (Charland, 2008).

There is a growing body of literature in the nursing discipline (Hartrick Doane, 2002; Johnson, Haigh, \& Yates-Bolton, 2006; Rassin, 2008) concerning values, attitudes, moral identity, and ethical conduct. An entire issue of the Journal of Nursing Management (Spence Laschinger, 2010) focused on the deleterious effect of incivility in the work environment. The issue highlighted how attitudes and interactions with colleagues and inter-disciplinary team members will impact one's own mental health, risk of burnout, or resignation from the professional work group, in addition to the possibility of compromising client care. Several articles concluded that positive working relationships matter for quality nursing and better patient outcomes.

\section{Three Factors That Influence our Ethical Conduct}

The larger culture influences ethical conduct. Examples of questionable ethical conduct and egregious ethical practices are rampant in $21^{\text {st }}$ century North American culture. Scandals involving prominent figures; steroid-fuelled cheating in Olympic and professional sports; greed in the financial industry; school and work place violence leading to shootings and the idiom "going postal" that has entered our vocabulary; and an accent on aggression and competition do affect us (Weingarten, 2003). 
A lack of civility in everyday social discourse is prevalent. Articles abound in the mainstream media about bullying and at least one tragic consequence, suicide. The Harvard Business Review printed an article in its 'breakthrough ideas' section dealing with eliminating psychological abuse, defined as "the sustained display of hostile verbal and nonverbal behaviors..." (Sutton, 2004, p. 19) in the workplace. The author of the article subsequently described an outpouring of feedback precipitated by the opportunity to talk about abusive employees and toxic work environments. Exploitation, deceit, entitlement, and a tendency to look the other way when impropriety is occurring are all too common. A lack of accountability often accompanies such acts of impropriety.

This is not to suggest that there are only grim stories to be told. Interest in examining ethical and moral conduct and a focus on acts of kindness (Saunders, 2014) exist and can inspire. The humanist community at Harvard University has developed a seminar format to address human interaction. One subject, Nonviolent Communication, focuses on "...learning how to speak to others - and to ourselves - more directly and compassionately" (Epstein, 2009, p. 128).

A second factor that will influence the evolution of our ethical practices is the culture of the program/agency in which we work. Do the values and goals of the workplace reflect core social work principles? Trends in the recent past of funding cuts, cost containment (Cummings, Cummings, \& O'Donahue, 2009; Steinberg \& Luce, 2005), downsizing, and increased caseloads can be a recipe for burnout among staff (Courtois \& Ford, 2013). Attention to core values and principles can suffer accordingly.

The leadership of the program/agency, indeed the organization itself (Liefooghe \& MacDavey, 2001), have responsibility for the culture of the work environment and for promoting an ethical culture (Kotter, 2007; Nembhard \& Edmondson, 2006; Toor \& Ofori, 2009). This includes “...establishing clear expectations of ethical conduct” (Bell \& Breslin, 2008, p. 96). “...employers not only have a moral obligation to fairly treat employees regarding wages and benefits, but also to treat the employees with sufficient dignity as persons. Emotionally abusive behaviors would violate these obligations" (Keashly, 1998, p. 95). "...ethical leaders do more than show followers what is right or wrong - if they behave authentically, they are also able to have greater influence over subordinates because they are operating ethically" (Hunter, 2012, p. 81).

Not all leaders accept this responsibility. Worse, leaders may condone or model bullying, entitled, or abusive practices. A leader may embody sadistic impulses (Peck, 1997). Real harm is perpetrated when the organization or individual leaders do not facilitate ethical practices. The culture of the work environment may then be toxic. The betrayal of acceptable standards of conduct in a workplace relationship between a supervisor and employee can result in the development of complex trauma for the victim of such behavior (Courtois \& Ford, 2013). Over time, the repercussions for staff and clients escalate. Silence emerges (Wall \& Austin, 2008) out of fear or actual threat of reprimand. Individuals may be forced to leave the employment position.

A third factor which influences ethical conduct is the social work ethos. A goal of most professions is to "...instill the implicit assumptions, values and behaviors necessary to be a certified or licensed member" (Hadjistavropoulos, 2003, p. 98). This underscores 
the importance of imparting practices that are sanctioned and valued in social work (Leighninger, 2000). The Canadian Association of Social Workers' ([CASW], 2005) Code of Ethics sets out an ethical responsibility to relate to colleagues with "respect, integrity and courtesy..." (p. 13). The pursuit of social justice has also been a core value of social work in the United States since the early $20^{\text {th }}$ century, and discussions about justice go back to the ancient Greek philosophers, Plato and Aristotle (Reisch, 2002). It does matter that we conduct ourselves, not just with our clients, but in all spheres of social work practice, in accord with these principles. Just as "there's no such thing as business ethics - there's only ethics" (Maxwell, 2003, preface), it is folly to think that we can maintain one standard with clients while having a different standard of conduct with colleagues. Moral sensitivity to the complexity in our lives and the real differences that exist between people enhances our commitment to one another (Jaeger, 2001).

Closely associated to the concept of justice is fairness (Rawls, 1971) and "...fairness (equity) is a basic issue that runs through the course of human history in all cultures" (Goldberg, 2000, p. 41). Consideration of fairness in our relationships connects to the concept of reciprocity, which suggests that beyond personal gain in an interaction, there are corresponding "...principles of reciprocity that guide healthy human interactions" (Young, Klosko, \& Weishaar, 2003, p. 236). “...[I]deals of fairness and reciprocity underwrite all contract-based systems of morality..." (Appiah, 2008, p. 135).

Unfortunately, as we delve more deeply into core themes such as ethics and social justice and how to promote congruence between the stated concept and reality, a number of dilemmas quickly emerge. A review of the literature on either ethics or social justice reveals that there is neither a uniform nor precise understanding of either social justice (Hong \& Hodge, 2009; Reisch, 2013) or ethics (Weinberg \& Campbell, 2014). Relationships with both clients and colleagues are inevitably complex and require an understanding and examination of context. The lack of clear consensus or objective truth regarding any of these core concepts amplifies the difficulty in entering into discussion and agreed upon action or rules of conduct. However, as we engage one another in the "struggle to translate the profession's compelling ethical imperative into real world terms" (Reisch, 2013, p. 718), there is a dynamic opportunity to bring real meaning to the experience of living values such as justice, ethical practice, and respect.

Among the common transgressions in the work place is how oblivious staff can be to stark unfairness. Issues of rivalry, ambition, and resentment can arise in social work and may account for such unfairness and disregard for reciprocity. These are all problems stemming from individuals' focus on how their actions affect only themselves, not their colleagues. However, considering consequential ethics suggests that the consequences of our actions are part of the process of forming an ethical judgment (Singer, 1994). Consequentialism suggests that we honor our values (McNaughton \& Rawling, 1992) and promote them through our actions (Pettit, 1989). Hence, if we value ethical practices, respect for people, and social justice, right action in given situations requires that our actions are directed at ends consistent with the promotion of such principles. Consideration of consequential ethics calls for a discussion of obligations (SinnottArmstrong, 2005), specifically, the moral obligation to act in ways that do not cause harm to others (Sinnott-Armstrong, 2009). For example, one individual's ambition can result in 
a poor outcome when considering the consequences for the larger staff group. The thrust of the moral obligation as suggested in the latter article requires consideration of the harm that is caused. This can incorporate reflection and real dialogue about treating one another fairly in the workplace. This is not an easy discussion if it involves examining advantages vis-à-vis disadvantages among colleagues. Such discussion can move us into the realm of virtue ethics, which focuses on the individual's character rather than an action. Virtue ethics helps us to examine how we learn to develop preferred character traits. Social work educators have a role in supporting the development of moral character and virtue (Holmstrom, 2014). As we learn to behave well routinely particular virtues will become ingrained (Gardiner, 2003).

\section{Two Dilemmas That Cue Us to Ethical Considerations}

This article will now examine two of the dilemmas and transgressions we can encounter in the workplace. These are bullying and an environment that overlooks or condones discourteous deportment among staff. These examples illustrate the challenge in maintaining congruence between social work values and workplace practices.

Such deleterious conduct is by no means a fixture in all work environments. Nor are these the only examples of dilemmas encountered in a work environment. What motivates or allows such conduct to flourish is beyond the scope of this article. However, these two dilemmas contextualize ideas raised for discussion.

A search of the term "workplace bullying" in the academic literature will produce copious references (Agervold \& Mikkelsen, 2004; Aquino \& Thau, 2009; Liefooghe \& MacDavey, 2001; Samnani \& Singh, 2012; Vega \& Comer, 2005). Bullying is a form of interpersonal violence (Crawford, 1997; Lipman, 2003). Acknowledging this idea should give all social workers pause to reflect on their behavior toward one another. One risk in attempting to address such unsavory interactions is that the perpetrators will engage in escalating acts to avoid accountability. Colleagues may be recruited to engage in mobbing behavior (Zapf, Knorz, \& Kulla, 1996), “...ganging up on someone, bullying, or psychological terror" (Leymann \& Gustafsson, 1996, p. 252). Mobbing behavior involves hostile communication frequently (weekly) and over time (six months) which can cause "...considerable psychological, psychosomatic and social suffering" (Leymann \& Gustafsson, 1996, p. 252). One aim of such action may be to deflect examination of the contentious conduct. Finding ways to ensure "... secrecy and silence are the perpetrator's first line of defense" (Herman, 1992, p. 8). Judith Herman's seminal analysis of common behaviors of perpetrators and victims of violence also offers sobering reflection in relation to confrontational interactions in the workplace.

Bullying is but one type of victimizing behavior in the workplace (Aquino \& Thau, 2009), along with mobbing, incivility, emotional abuse, and harassment. There are several definitions of workplace bullying including that “...it must be perceived by the victim as oppressive, unfair, humiliating, undermining, threatening, difficult to defend against..." (Djurkovic \& McCormack, 2008, p. 405). Such behaviors occurring over an extended period of time is considered an additional characteristic of bullying. Workplace bullying is deemed to be a contemporary problem, characterized by hostile and prolonged 
mistreatment toward a person who does not welcome such interaction (Appelbaum, Semerjian, \& Mohan, 2012). The intent to do harm and the depth of pain that results from bullying can render victims demoralized and powerless as the behavior persists (Vega \& Comer, 2005).

Suicide is one tragic result of workplace bullying (Brotheridge \& Lee, 2006; Samnani $\&$ Singh, 2012). More recently, media attention to completed suicide as an outcome of bullying in schools and in cyberspace toward individuals with an alternate lifestyle is also prominent. Perhaps the greatest irony of all is to walk through corridors in hospitals or entrances to medical centers and see signs announcing that "abuse of staff will not be tolerated." It is not just 'the public' that needs to respect such commands.

A second dilemma or transgression which can illustrate the difficulty in maintaining congruence between social work values and workplace practices involves discourteous deportment in the work environment. It is difficult to understand how well-educated individuals, presumably committed to working in the helping professions, can so often and so cavalierly engage in discourteous, disrespectful conduct toward colleagues. Emotional shunning (the silent treatment), shouting at colleagues, or walking around with a baleful expression, effectively distancing colleagues, is not just discourtesy. Incivility and even emotional abuse (Keashly, 1998) are being practiced. The long-term psychological distress of emotional abuse can be even more deleterious than that caused by sexual or physical abuse (Goldsmith \& Freyd, 2005; Kaplan, Pelcovitz, \& Labruna, 1999; Rees, 2010). In a culture that oftentimes rewards posturing, aggression, and a macho deportment, it is troubling to see the success of social workers who will imitate a 12 year old schoolyard bully in their interactions with colleagues. Responding effectively, without resorting to similar tactics, is a challenge.

Akin to the scourge of bullying in the workplace, incivility is a concept receiving increasing attention (Cortina, 2008; Cortina \& Magley, 2009; Cortina, Magley, Williams, \& Langhout, 2001; Gallus, Bunk, Matthews, Barnes-Farrell, \& Magley, 2014; Pearson \& Porath, 2005). An array of behaviors are identified as constituting incivility, including that they are "...in violation of workplace norms for mutual respect" (Cortina et al., 2001, p. 64), demonstrate "...disregard for others" (Pearson, Andersson, \& Wegner, 2001, p. 1387), have a negative impact on the work environment and result in harming the target (Cortina et al., 2001; Gallus et al., 2014).

Canadian health care providers engaged in project CREW (Civility, Respect and Engagement at Work) focused on reducing incivility, burnout, and improving social relationships among staff groups (Leiter, Spence Laschinger, Day, \& Oore, 2011). The project arose out of the acknowledged prevalence of incivility in organizations and the desire to promote civility - "...identified as courteous and considerate behavior toward other people" (Leiter et al., 2011, p. 1258). The authors contend that civility and respect are defining qualities of an organization, the absence of which connotes numerous negative outcomes. The focus on developing positive social behavior among members of the work group was seen as reducing burnout and creating more positive attitudes at work. In follow-up surveys one year later it was determined that the improvements (CREW) can become self-sustaining if they are continued after the formal intervention 
has been concluded (Leiter, Day, Oore, \& Spence Laschinger, 2012). The authors suggested that improvements in civility likely enhance the self-esteem and energy of staff and that a sense of psychological safety evolves in a respectful work environment, further promoting civility. A final implication noted in the latter article is that enduring change is more likely when explicit behaviors that reflect civility are established.

It is disconcerting to be in a social work group or a department where multiple staff, even supervisors or senior managers, will acknowledge discomfort in addressing a relentless pattern of surliness and disrespect being communicated by a few staff, often for years. Our collective awkwardness in addressing a persistent, demeaning tone contributes to a toxic environment and the departure of staff who simply do not wish to engage in such incivility (Cortina \& Magley, 2009; Djurkovic \& McCormack, 2008). A "hear no evil, see no evil" practice exacerbates the challenge of maintaining congruence, as staff not subject to transgressions, and even individuals in positions of significant seniority, will prefer to know nothing about impropriety, so long as they are not directly impacted. "Do not ask what you do not want to know" is held out as an effective management strategy to side-step impropriety, or to remain apart from the complex interactions that occur in a staff group. Such stances neither promote values nor demonstrate respect for persons (Pettit, 1989), each important considerations when determining our conduct. Communicating indifference to impropriety and abuse risks dehumanizing those subjected to such treatment. Perhaps fear of reprisal, self-preservation, or confusion about the complex principle of neutrality, prompt individuals to say and do nothing while colleagues are treated with disrespect or driven from their jobs. This is not neutrality. The risk is that we are collectively diminished when incivility and impropriety goes unchecked. Colleagues can help targets of impropriety make sense of their experience (Olson-Buchanan \& Boswell, 2008). The quality of social support from colleagues will impact the individual's stress (Chiaburu \& Harrison, 2008) and decisions to leave the workplace (Djurkovic \& McCormack, 2008).

An opportunity to marry personal responsibility to collective responsibility presents itself when we witness incivility, abuse, and bullying behavior. The poem 'For Whom the Bell Tolls' (Donne, 1839, pp. 574-575) inspires the idea that we are all interconnected. Our social conscience is strengthened when we stand beside, not turn away from our colleagues when they are harmed. Ethical deportment is all our concern.

\section{Suggested Remedies}

This article will now consider steps to support ethical practices. From a systemic point of view, specific values and a code of conduct can be articulated as part of the program mandate. How these are implemented to demonstrate that they are not mere words, but guidelines for interaction, is an important consideration. The congruence between words and actions is a virtue (Freire \& Moch, 1987). The leadership of the program/agency has a unique opportunity to set the tone for deportment in the workplace, not just toward clients, but among colleagues. The responsibility of agency leaders in conducting themselves in a consistently dignified manner can set a strong example for the tone expected among staff of the agency (Hunter, 2012; Nembhard \& Edmondson, 2006; Toor \& Ofori, 2009). This important step will likely not suffice. It is also imperative that 
mechanisms to support the stated values and deportment be included in the agency charter. A commitment to accountability and a determination to enforce sanctions against those who choose to transgress the expectation of ethical conduct are essential. When the administrative leadership of a program/agency demonstrates the intention to "walk the talk" of a workplace environment informed by respect, fairness, and justice, the possibility of being part of a deeply meaningful work environment can be inspired. Closely resembling the inquiry of our client, "what do you want your life to stand for?" (Hayes, Follette \& Linehan, 2004, p. 22), we can recognize that we have a deeper choice in our life being about something. A collective sense of purpose can transcend the everyday mundane, further galvanizing individuals in their calling.

The Code of Ethics for social work and other disciplines in the helping professions can offer a similar example of commitment to our most hallowed values and a determination to enforce them where necessary. Having confidence that the professional social work regulatory body has mechanisms to support individual staff in addressing ethical misconduct can help to address impropriety in those situations where the workplace administration is unwilling to do so. The model for such an approach is wellestablished in respective professional Codes of Conduct, for example, with a protocol for investigating and, where appropriate, sanctioning a social worker charged with ethical impropriety toward a client. Holding staff accountable for breaches in ethical conduct could be a progressive step toward creating a professional discipline that exemplifies a commitment to respect, dignity, and fairness. Such steps might initially serve as a deterrent, eventually becoming a standard to which all might aspire.

The focus will now shift to the individual's self-reflection and inviting dialogue with colleagues. Considering individual contributions to the work environment guards against the individual worker feeling overwhelmed by systemic factors they feel powerless to change. An emphasis on individual actions congruent with social work values and principles also reflects the reality of more front-line staff than administrators in a program, hence the opportunity to make contributions to the creation of a work environment that matters in our collective lives.

Achieving congruence between values and principles and our everyday interactions is a complex process. Making time to talk, being present in the moment, being authentic, practicing the skills and attitudes we value, and being attentive to the real effects that we have on one another all matter. Regular meetings and attention to the nuances of communication can contribute to a healthy work environment. Fostering respect and a commitment to practices of fairness, justice, and simple decency will further support a healthy workplace. Policy can outline specific steps to demonstrate respect and healthy communication. Practice occurs as social workers shift from talking about these terms to focusing on how we actually speak to and treat one another in daily interactions. Exercises to support staff in developing new, explicit ways of interacting (Leiter, Day, et al., 2012; Leiter, Spence Laschinger, et al., 2011) can sensitize all concerned to their impact on colleagues. Facilitating dialogue has a rich tradition in teaching social work ethics, raising critical awareness in training (Hugman, 2005; Sakamoto \& Pitner, 2005), and promoting collaboration in discussion about complex issues for which there is "no 
clear right and wrong" (Weinberg \& Campbell, 2014, p. 45). An ethical workplace is nurtured as such processes evolve.

In the current health care and social services climate, it is a lot to ask of social workers that they also make time for reflection and discussion beyond the direct care of clients. However, an experiential supposition of the author is that the quality of care provided for clients can only be as good as the health of the multi-disciplinary staff offering that care. Nurturing congruence between our sacred values and our actual daily practices toward one another can support a robust staff not compromised by demoralization or burnout.

There are four questions I propose be asked when considering the ethics of our actions. First, are we employing 'The Golden Rule', some variation of which can be found in most major religions and throughout human history (Armstrong, 2010; Baumard \& Boyer, 2013; Epstein, 2009; Maxwell, 2003)? The Golden Rule is simply 'to do unto others as you would have others do unto you'. Caution is suggested in presuming The Golden Rule to be a panacea, as individuals may have varying ideas about how they wish to be treated (Sandel, 2009). Immanuel Kant's categorical imperative (Neiman, 2008) may be a more agreeable approach for some. This latter idea suggests that our actions be universalized. In other words, can we answer the question, what would happen if everyone were to act in the manner I am now acting? Alternately, the consequences of our action can be considered as a beacon to guide our behavior. By examining the consequences of an action and encouraging discussion of the implications of individual actions for the entire group, a dynamic and comprehensive exploration of ethical practices can evolve. In each instance, the idea is to raise our consciousness about how we wish to be treated and how we treat others.

A second question is to consider a more personal examination of the proposed behavior: what would it be like for me if I was treated in the manner that I am treating others? As a reverse form of empathy, this may assist us in paying attention to the real effects of our actions.

A third question is: how would I feel if everyone knew that I was acting in this manner? Our comfort level when answering this question is a useful barometer of the ethics of our actions.

A fourth question is: am I accountable for my actions and their consequences for colleagues? It is troubling to realize how frequently questionable conduct will occur, with no apparent thought or concern for the impact of one's actions on others. An absence of accountability may be accompanied by denial, disdain, or impunity with respect to the impact of our actions on colleagues. These are alarming warning signs about our ethical conduct. An inordinate focus on self-interest can deflect sensitivity to the inevitable impact of our actions on our colleagues. In a culture where the notion of entitlement is so prevalent, being accountable for our actions and their consequences takes character.

Further complicating this discussion is the realization of how difficult it is to arrive at a shared agreement about what constitutes social justice or fairness. There is no guarantee of a shared ethos or even a clear mandate beyond lofty ideals that may not readily 
translate into applicable behavior toward one another. A work situation, created by accident or design, which privileges one individual at the expense of another demands a great deal of both parties to engage in discussion and negotiation about redressing what may be perceived by only one party as an injustice. This can be an extraordinarily difficult discussion to enter into, calling for trust, genuineness, and a commitment to agree upon values and practices in the workplace.

How we speak to one another and how we negotiate our relational space can inform our ethics. Openness to a discussion with colleagues about our conduct and its impact is a further check on the propriety of our actions. Such practices require self-awareness and sensitivity. Karen Armstrong's examination of necessary steps to a compassionate life identifies the eighth step as "how we should speak to one another" (Armstrong, 2010, pp. 131-132). Armstrong notes that this takes time, is hard work and must "...be conducted in a kindly and compassionate manner" (p. 132). Social workers are generally wellinformed about the nuances of communication expressed through words, tone, body language, and eye contact. Individuals can decline to resort to demeaning language or personal slurs. Choosing language and tone that invites mutual respect, dialogue, and collaboration speaks volumes. It also takes considerable neural energy to interrupt old patterns and to establish new habits that are more consistent with communication that is respectful and compassionate (Newberg \& Waldman, 2012). With every word and sentence we speak we are sending verbal and nonverbal messages about how we intend to be with other people. Our relationships can thrive as we practice nuanced communication that invites mutual respect and compassion.

It is not a matter of presuming to dictate how social workers will interact. Rather, it is a matter of providing a forum where individuals are invited to have an authentic and open discussion about how we intend to be with one another. Multiple factors such as personal inclination, ambition, experience, self-interest, and informal alliances deserve reflection. Exploration of interactions among colleagues that identify uncertainty, disagreement, and challenges in creating a preferred environment can be encouraged.

An emphasis on opening up a dialogue among staff of the work environment can guard against a limitation in self-reflection. The process of self-reflection, while a necessary precursor to change, does not ensure engagement with colleagues. When we commit to meaningfully talk to one another we enter into a spirit of community; "...it is in dialogical encounters that one's ethical understanding takes shape and that these must be true encounters..." (Austin, 2007, p. 85). Bringing ethical practice to life involves a commitment to encounter one another with genuineness.

In recent years interest in such concepts as mindfulness and being present in the moment (Kabat-Zinn, 1990) has increased. These practices can enhance our attention to interactions and communication with colleagues. We can commit ourselves to being aware of the real effects of our actions toward one another (White, 1996). This includes nurturing respect in our relationships with one another, respect for the differences that inevitably arise from negotiation, and increased attention to the relationships we wish to create and maintain with our colleagues (Bergum \& Dossetor, 2005). 


\section{Conclusion}

Ethics do matter, and on a daily basis in our workplace. The commitment to ethical practices, grounded in congruence between social work values and our everyday acts, can promote a healthy work environment. This can sustain the individual worker and enhance the care of clients. The willingness to engage in genuine dialogue with colleagues about our ethical practices toward one another contributes to a shared meaning and can be a part of the lived experience at work. Such practices offer an opportunity to make a difference and set a standard of which we can be collectively proud.

\section{References}

Agervold, M., \& Mikkelsen, E. G. (2004). Relationships between bullying, psychosocial work environment and individual stress reactions. Work \& Stress, 18(4), 336-351.

Appelbaum, S., Semerjian, G., \& Mohan, K. (2012). Workplace bullying: Consequences, causes and controls (part two). Industrial and Commercial Training, 44(6), 337-344.

Appiah, K. (2008). Experiments in ethics. Cambridge, MA: Harvard University Press.

Aquino, K., \& Thau, S. (2009). Workplace victimization: Aggression from the target's perspective. Annual Review of Psychology, 60, 717-741.

Armstrong, K. (2010). Twelve steps to a compassionate life. New York, NY: Alfred A. Knopf.

Austin, M. (Ed.). (2013). Social justice and social work: Rediscovering a core value of the profession. Los Angeles, CA: Sage Publications.

Austin, W. (2007). The ethics of everyday practice: Healthcare environments as moral communities. Advances in Nursing Science, 30(1), 81-88.

Baumard, N., \& Boyer, P. (2013). Explaining moral religions. Trends in Cognitive Sciences, 17(6), 272-280.

Bell, J., \& Breslin, J. (2008). Healthcare provider moral distress as a leadership challenge. JONA's Healthcare Law, Ethics, and Regulation, 10(4), 94-97.

Bergum, V., \& Dossetor, J. (2005). Relational ethics: The full meaning of respect. Hagerstown, PA: University Publishing Group.

Boland, K. (2006). Ethical decision-making among hospital social workers. Journal of Social Work Values and Ethics, 3(1). Retrieved from http://www.jswvearchives.com/content/view/27/44

Brotheridge, C., \& Lee, R. (2006). Examining the relationship between perceived work environment and workplace bullying. Canadian Journal of Community Mental Health, 25(2), 31-44.

Canadian Association of Social Workers [CASW]. (2005). Guidelines for ethical practice. Retrieved from http://casw- 
acts.ca/sites/default/files/attachements/CASW_Guidelines $\% 20$ for $\% 20$ Ethical $\% 20$ Pra ctice.pdf

Charland, L. (2008). By what authority? Conflicts of interest in professional ethics. Journal of Ethics in Mental Health, 3(2), 1-3.

Chiaburu, D., \& Harrison, D. (2008). Do peers make the place? Conceptual synthesis and meta-analysis of coworker effects on perceptions, attitudes, OCBs, and performance. Journal of Applied Psychology, 93(5), 1082-1103.

Congress, E. (2000). What social workers should know about ethics: Understanding and resolving practice dilemmas. Advances in Social Work, 1(1), 1-22.

Cortina, L. (2008). Unseen injustice: Incivility as modern discrimination in organizations. Academy of Management Review, 33(1), 55-75.

Cortina, L., \& Magley, V. (2009). Patterns and profiles of response to incivility in the workplace. Journal of Occupational Health Psychology, 14(3), 272-288.

Cortina, L., Magley, V., Williams, J., \& Langhout, R. (2001). Incivility in the workplace: Incidence and impact. Journal of Occupational Health Psychology, 6(1), 64-80.

Courtois, C., \& Ford, J. (2013). Treatment of complex trauma: A sequenced, relationship-based approach. New York, NY: The Guilford Press.

Crawford, N. (1997). Bullying at work: A psychoanalytic perspective. Journal of Community \& Applied Social Psychology, 7, 219-225.

Cummings, N., Cummings, J., \& O’Donahue, W. (2009). We are not a healthcare business: Our inadvertent vow of poverty. Journal of Contemporary Psychotherapy, 39, 7-15.

Djurkovic, N., \& McCormack, D. (2008). Workplace bullying and intention to leave: The moderating effect of perceived organizational support. Human Resource Management Journal, 18(4), 405-421.

Donne, J. (1839). The works of John Donne (Vol. III, H. Alford, Ed.). London: John W. Parker.

Epstein, G. (2009). Good without God. New York, NY: HarperCollins.

Ferguson, I., \& Lavalette, M. (2007). "Dreaming a great dream": Prospects for a new, radical social work. Canadian Social Work Review, 24(1), 55-68.

Freire, P., \& Moch, M. (1987). A critical understanding of social work. Journal of Progressive Human Services, 1(1), 3-9.

Gallus, J., Bunk, J., Matthews, R., Barnes-Farrell, J., \& Magley, V. (2014). An eye for an eye? Exploring the relationship between workplace incivility experiences and perpetration. Journal of Occupational Health Psychology, 19(2), 143-154.

Gardiner, P. (2003). A virtue ethics approach to moral dilemmas in medicine. Journal of Medical Ethics, 29, 297-302. 
Gerdes, K. (2009). A social work model of empathy. Advances in Social Work, 10(2), 114-127.

Goldberg, C. (2000). The evil we do: The psychoanalysis of destructive people. New York, NY: Prometheus Books.

Goldsmith, R., \& Freyd, J. (2005). Effects of emotional abuse in family and work environments. Journal of Emotional Abuse, 5(1), 95-123.

Hadjistavropoulos, T. (2003). The ethical ideologies of psychologists and physicians: A preliminary comparison. Ethics \& Behavior, 13(1), 97-104.

Hartrick Doane, G. (2002). Am I still ethical? The socially-mediated process of nurses' moral identity. Nursing Ethics, 9(6), 623-635.

Hayes, S., Follette, V., \& Linehan, M. (Eds.). (2004). Mindfulness and acceptance. New York, NY: Guilford Press.

Hepworth, D., Rooney, R., Rooney, G. D., Strom-Gottfried, K., \& Larsen, J. A. (2010). Direct social work practice: Theory and skills ( $8^{\text {th }}$ ed.). Belmont, CA: Brooks/Cole.

Herman, J. (1992). Trauma and recovery. New York, NY: Basic Books.

Holmstrom, C. (2014). Suitability for professional practice: Assessing and developing moral character in social work education. Social Work Education, 33(4), 451-468.

Hong, P. Y., \& Hodge, D. (2009). Understanding social justice in social work: A content analysis of course syllabi. Families in Society: The Journal of Contemporary Social Services, 91(1), 212-219.

Hugman, R. (2005). Exploring the paradox of teaching ethics for social work practice. Social Work Education: The International Journal, 24(5), 535-545.

Hunter, S. (2012). (Un)Ethical leadership and identity: What did we learn and where do we go from here? Journal of Business Ethics, 107, 79-87.

Jaeger, S. (2001). Teaching health care ethics: The importance of moral sensitivity to moral reasoning. Nursing Philosophy, 2, 131-142.

Johns, A., \& Crockwell, L. (2009). Reflecting on the use of the Code of Ethics in SW practice: A Newfoundland and Labrador perspective. Journal of Social Work Values and Ethics, 6(2). Retrieved from http://www.jswvearchives.com/content/view/122/68/

Johnson, M., Haigh, C., \& Yates-Bolton, N. (2006). Valuing of altruism and honesty in nursing students: A two-decade replication study. Journal of Advanced Nursing, 57(4), 366-374.

Kabat-Zinn, J. (1990). Full catastrophe living. New York, NY: Random House.

Kaplan, S., Pelcovitz, D., \& Labruna, V. (1999). Child and adolescent abuse and neglect research: A review of the past 10 years. Part I: Physical and emotional abuse and 
neglect. Journal of the American Academy of Child \& Adolescent Psychiatry, 38(10), 1214-1222.

Keashly, L. (1998). Emotional abuse in the workplace: Conceptual and empirical issues. Journal of Emotional Abuse, 1(1), 85-117.

Kotter, J. (2007). Leading change: Why transformation efforts fail. Harvard Business Review, 85(1), 96-103.

Landau, R. (2000). Ethical dilemmas in general hospitals: Differential perceptions of direct practitioners and directors of social services. Social Work in Health Care, 30(4), 25-44.

Leighninger, L. (2000). Creating a new profession: The beginnings of social work education in the United States. Alexandria, VA: Council on Social Work Education.

Leiter, M., Day, A., Oore, D., \& Spence Laschinger, H. (2012). Getting better and staying better: Assessing civility, incivility, distress, and job attitudes one year after a civility intervention. Journal of Occupational Health Psychology, 17(4), 425-434.

Leiter, M., Spence Laschinger, H., Day, A., \& Oore, D. (2011). The impact of civility interventions on employee social behavior, distress and attitudes. Journal of Applied Psychology, 96(6), 1258-1274.

Leymann, H., \& Gustafsson, A. (1996). Mobbing at work and the development of posttraumatic stress disorders. European Journal of Work and Organizational Psychology, 5(2), 251-275.

Liefooghe, A., \& MacDavey, K. (2001). Accounts of workplace bullying: The role of the organization. European Journal of Work and Organizational Psychology, 10(4), 375392.

Lipman, E. (2003). Don't let anyone bully you into thinking bullying is not important. Canadian Journal of Psychiatry, 48(9), 575-576.

MacDonald, A. (2007). Should social workers meet a higher standard? The Advocate, 32(2), 14. Retrieved from http://www.acsw.ab.ca/advocate/advocate_summer_2007

Manning, S. (1997). The social worker as moral citizen: Ethics in action. Social Work, 42(3), 223-230.

Mattison, M. (2000). Ethical decision-making: The person in process. Social Work, 45(3), 201-212.

Maxwell, J. (2003). There's no such thing as business ethics: There's only one rule for making decisions. New York, NY: Warner Books.

McNaughton, D., \& Rawling, P. (1992). Honoring and promoting values. Ethics, 102, July, 835-843.

Mitchell, P., Wynia, M., Golden, R., NcNellis, B., Okun, S., Webb, C. E., Rohrbach, V., \& Von Kohorn, I. (2012). Core principles \& values of effective team-based health 
care. Discussion paper. Washington, DC: Institute of Medicine. Retrieved from www.iom.edu/tbc.

Neiman, S. (2008). Moral clarity: A guide for grown-up idealists. Orlando, FL: Harcourt Inc.

Nembhard, I., \& Edmondson, A. (2006). Making it safe: The effects of leader inclusiveness and professional status on psychological safety and improvement efforts in health care teams. Journal of Organizational Behaviour, 27, 941-966.

Newberg, A., \& Waldman, R. A. (2012). Words can change your brain: 12 conversation strategies to build trust, resolve conflict and increase intimacy. New York, NY: Plume Book.

Olson-Buchanan, J., \& Boswell, W. (2008). An integrative model of experiencing and responding to mistreatment at work. Academy of Management Review, 33(1), 76-96.

Pearson, C., Andersson, L., \& Wegner, J. (2001). When workers flout convention: A study of workplace incivility. Human Relations, 54(11), 1387-1419.

Pearson, C., \& Porath, C. (2005). On the nature, consequences and remedies of workplace incivility: No time for "nice"? Think again. Academy of Management Executive, 19(1), 7-19.

Peck, M. S. (1997). Denial of the soul: Spiritual and medical perspectives on euthanasia and mortality. New York, NY: Harmony Books.

Pettit, P. (1989). Consequentialism and respect for persons. Ethics, 100(1), 116-126.

Rassin, M. (2008). Nurses' professional and personal values. Nursing Ethics, 15(5), 614630.

Rawls, J. (1971). A theory of justice. Cambridge, MA: Harvard University Press.

Reamer, F. G. (2001). Ethics education in social work. Alexandria, VA: Council on Social Work Education.

Reamer, F. G. (2013). Social work values and ethics (4 ${ }^{\text {th }}$ ed.). New York, NY: Columbia University Press.

Rees, C. (2010). Understanding emotional abuse. Archives of Disease in Childhood, 95(1), 59-67.

Reisch, M. (2002). Defining social justice in a socially unjust world. Families in Society: The Journal of Contemporary Human Service, 83, 343-354.

Reisch, M. (2013). Social work education and the neo-liberal challenge: The US response to increasing global inequality. Social Work Education, 32(6), 715-733.

Reisch, M., \& Jani, J. (2012). The new politics of social work practice: Understanding context to promote change. British Journal of Social Work, 42, 1132-1150.

Rountree, M., \& Pomeroy, E. (2010). Bridging the gaps among social justice, research, and practice. Social Work, 55(4), 293-295. 
Sakamoto, I., \& Pitner, R. (2005). Use of critical consciousness in anti-oppressive social work practice: Disentangling power dynamics at personal and structural levels. British Journal of Social Work, 35, 435-452.

Samnani, A., \& Singh, P. (2012). 20 years of workplace bullying research: A review of the antecedents and consequences of bullying in the workplace. Aggression and Violent Behavior, 17, 581-589.

Sandel, M. (2009). Justice: What's the right thing to do? New York, NY: Farrar, Straus and Giroux.

Saunders, G. (2014). Congratulations, by the way. New York, NY: Random House.

Singer, P. (Ed.). (1994). Ethics. New York, NY: Oxford University Press.

Sinnott-Armstorng, W. (2009). How strong is this obligation? An argument for consequentialism from concomitant variation. Analysis, 69(3), 438-442.

Sinnott-Armstrong, W. (2005). You ought to be ashamed of yourself (when you violate an imperfect moral obligation). Philosophical Issues, 15, 193-208.

Spence Laschinger, H. K. (Ed.). (2010). Positive working relationships matter for better nurse and patient outcomes [Special issue]. Journal of Nursing Management, 18(8), 875-1086.

Steinberg, E., \& Luce, B. (2005). Evidence based? Caveat emptor! Health Affairs, 24(1), 80-92.

Sutton, R. (2004). More trouble than they're worth. Harvard Business Review, 82(2), 1920.

Toor, S-u-R., \& Ofori, G. (2009). Ethical leadership: Examining the relationships with full range leadership model, employee outcomes, and organizational culture. Journal of Business Ethics, 90, 533-547.

Vega, G., \& Comer, D. (2005). Sticks and stones may break your bones, but words can break your spirit: Bullying in the workplace. Journal of Business Ethics, 58, 101-109.

Wall, S., \& Austin, W. (2008). The influence of teams, supervisors and organizations on healthcare practitioners' abilities to practice ethically. Nursing Research, 21(4), 8599.

Weinberg, M., \& Campbell, C. (2014). From codes to contextual collaborations: Shifting the thinking about ethics in social work. Journal of Progressive Human Services, 25(1), 37-49.

Weingarten, K. (2003). Common shock. Witnessing violence every day: How we are harmed, how we can heal. New York, NY: New American Library.

White, M. (1996). On ethics and the spiritualities of the surface. In M. Hoyt (Ed.), Constructive therapies (Vol. 2, pp. 33-59). New York, NY: The Guilford Press. 
Young, J., Klosko, J., \& Weishaar, M. (2003). Schema therapy: A practitioner's guide. New York, NY: Guilford Press.

Zapf, D., Knorz, C., \& Kulla, M. (1996). On the relationship between mobbing factors, and job content, social work environment, and health outcomes. European Journal of Work and Organizational Psychology, 5(2), 215-237.

\section{Author note}

Address correspondence to: Peter J. O'Brien, MSW, RSW, Shared Mental Health Care, Alberta Health Services, Sheldon M. Chumir Health Centre, $1213-4^{\text {th }}$ St. SW, Calgary, Alberta, T2R 0X7. Email: peter.obrien@albertahealthservices.ca 